\title{
Association of p73 gene G4C14-A4T14 polymorphism and MDM2 gene SNP309 with non-small cell lung cancer risk in a Chinese population
}

\author{
WEN LI ${ }^{1}$, SHUANG SHUANG WANG ${ }^{1}$, JING DENG $^{2}$ and JIAN XIN TANG ${ }^{1}$ \\ ${ }^{1}$ Key Laboratory of Green Packaging and Application of Biological Nanotechnology; ${ }^{2}$ College of Packaging \\ and Material Engineering, Hunan University of Technology, Zhuzhou, Hunan 412007, P.R. China
}

Received October 7, 2015; Accepted March 17, 2017

DOI: $10.3892 / 01.2017 .6327$

\begin{abstract}
The present study aimed to investigate the association of p73 G4C14-A4T14 polymorphism and murine double minute 2 (MDM2) $309 \mathrm{~T} / \mathrm{G}$ single nucleotide polymorphisms (SNPs) with the risk of developing non-small cell lung cancer (NSCLC) in Sothern China. The p73 and MDM2 genotypes of peripheral blood DNA from 186 patients with NSCLC and 196 normal controls were detected by polymerase chain reaction (PCR) with confronting two-pair primers (CTPP) and high resolution melting (HRM), respectively. The results of genotyping were consistent with those of direct sequencing. The p73 AT/AT [odds ratio $(\mathrm{OR})=0.46 ; 95 \%$ confidence interval $(\mathrm{CI})=0.22-0.97]$ and MDM2 TT $(\mathrm{OR}=0.48 ; 95 \%$ $\mathrm{CI}=0.26-0.86)$ genotypes were associated with a decreased risk of developing NSCLC compared with that of the p73 GC/GC and MDM2 GG genotypes, respectively. In addition, the interaction between the p73 and MDM2 polymorphisms reduced the risk of developing NSCLC in multiple ways $(\mathrm{OR}=0.13 ; 95 \% \mathrm{CI}=0.03-0.59)$ for subjects carrying both the p73 AT/AT and MDM2 TT genotypes. Therefore, the SNP in p73 G4C14-A4T14 and the MDM2 309 polymorphism may be markers of genetic susceptibility to NSCLC in a Chinese population, and there is a possible gene-gene interaction involved in the incidence of NSCLC.
\end{abstract}

\section{Introduction}

Non-small cell lung cancer (NSCLC), the main type of lung cancer, is one of the most common malignant tumors in males worldwide (1). The incidence and mortality of lung cancer is currently increasing in China, and the most common risk factors are involved environmental, occupational and

Correspondence to: Dr Jing Deng, College of Packaging and Material Engineering, Hunan University of Technology, 88 Taishan Road, Tianyuan, Zhuzhou, Hunan 412007, P.R. China

E-mail: dengjing0102@yahoo.com

Key words: p73, MDM2, polymorphism, NSCLC genetic (2-4). Environmental factors, including tobacco smoking, air pollution, contamination in drinking water and food, are passing through the natural barriers such as shin and metabolic elimination; the environmental carcinogens enter cells, damage DNA and destroy the balance among growth, differentiation and apoptosis of the cells, which cause carcinogenesis $(3,4)$.

It has been well established that lung cancer is a complex disease that is highly correlated with environmental pollutants in the general population; in addition, genetic factors are known to plays an important role in this disease (2-4). Studies on the association between gene variants and lung cancer will contribute to clarify the underlying mechanisms of lung cancer, including its development, and will potentially provide therapeutic targets that are important in the diagnosis and prognosis of lung cancer.

p73, one of the p53 family members, is located at the human chromosome $1 \mathrm{p} 36.33$, and shares relatively high structural and functional homology with p53 $(5,6)$. As a candidate tumor-suppressor gene, it encodes two different proteins, namely the transcriptionally active full-length TAp73 and the $\mathrm{NH}_{2}$ terminally truncated dominant-negative $\Delta \mathrm{Np} 73$ (6), which have remarkable similarity with p53 in their DNA-binding, transactivation and oligomerization domains (5). G4C14 and A4T14, the two single nucleotide polymorphisms (SNPs) of p73 at positions $4(\mathrm{G}>\mathrm{A})$ and $14(\mathrm{C}>\mathrm{T})$ (rs2273953 and rs1801173, respectively), are located upstream of the initiating codon AUG in exon 2, and potentially influence the gene expression of p73 by forming a stem-loop structure $(5,7)$. Various studies have investigated p73 polymorphisms and cancer risk in a variety of tumors (8-14), including lung cancer (15-17), but the conclusions of those studies were inconsistent.

The human homolog of mouse double minute 2 (MDM2) is known to act as a major negative regulator of p73. MDM2 is a nuclear phosphoprotein that binds to the $\mathrm{N}$-terminal TA domain of TAp73 and inhibits the transcription of p73 by interrupting its contact with the transcription adaptors/cofactors p300 and CREB-binding protein (18-20). An important polymorphism ( $>$ G, rs2279744), termed SNP309, has been identified to be located in the MDM2 intrinsic p53-response promoter (21-23). Cells carrying the SNP309 GG genotype were observed to exhibit an increased affinity for the transcriptional activator 
specificity protein 1 (Sp1), which resulted in higher messenger RNA and protein expression levels of MDM2 compared with those in cells carrying the SNP309 TT genotype $(21,22)$. Those results demonstrated that SNP309 T/G was associated with a decreased response to DNA-damaging agents and an accelerated tumorigenesis in both hereditary and sporadic cancer patients $(22,23)$, suggesting that SNP309 may contribute to individual differences in cancer susceptibility.

Several studies have shown that disruption of the p53-MDM2 interaction by the suppression of MDM2 expression can lead to p53 activation and tumor growth inhibition $(21,22)$. The p73 and MDM2 genes are involved in the genetics of the p53 signaling pathway in various tumors; however, their role in the tumorigenesis of NSCLC remains to be clarified. In the present study, the interaction between the p73 G4C14-A4T14 and MDM2 SNP309 polymorphisms was found to effect susceptibility to NSCLC in a Southern Chinese population.

\section{Materials and methods}

Study subjects and samples. The present case-control study consisted of 186 patients with NSCLC and 196 cancer-free controls. All subjects were consecutively recruited at the Central Hospital of Zhuzhou City (Zhuzhou, China) and Hunan Provincial Tumor Hospital (Changsha, China) between March 2013 and December 2014. All patients were histopathologically confirmed and had not received preoperative chemotherapy or radiotherapy. The cancer-free controls were randomly recruited from healthy individuals who underwent a cancer screening program in the same region and during the same period than the case patients. At recruitment, informed consent forms about the study were signed by all subjects, and each participant was interviewed to collect baseline data, including demographic factors, medical history, current or past tobacco use (yes or no) and alcohol consumption (yes or no). The research protocol was approved by the Institutional Review Board of the Central Hospital of Zhuzhou City and Hunan Provincial Tumor Hospital (Zhuzhou, China).

DNA extraction. Venous blood $(5 \mathrm{ml})$ from each subject was collected into Vacutainer (Hunan Ping'an Medical Machinery Technology Co., Ltd., Hunan, China) tubes containing EDTA and stored at $-70^{\circ} \mathrm{C}$. The extraction of genomic DNA was performed using a Dzup (Blood) Genomic DNA Isolation Reagent (Sangon Biotech Co., Ltd., Shanghai, China), in accordance with the manufacturer's protocol.

MDM2 SNP309. Polymorphism in MDM2 was determined by high resolution melting (HRM) (24). The primers used for quantitative polymerase chain reaction (PCR) analysis were $\mathrm{T}$, 5'-CTAGGGCTGCGGGGCCGATT-3'; G, 5'-GCGGGCTGG GCTAGGCTGCGGGGCCGTTG-3'; and common primer C, 5'-ACCCGACAGGCACCTGCGATC-3' (all forward). The PCR volume was $20 \mu \mathrm{l}$, and included SYBR-Green PCR Master Mix (Shanghai GeneCore BioTechnologies Co., Ltd., Shanghai, China; $10 \mu \mathrm{l})$, primer $\mathrm{T}(0.4 \mu \mathrm{l})$, primer $\mathrm{G}(0.1 \mu \mathrm{l})$, primer $\mathrm{C}(0.2 \mu \mathrm{l})$, double distilled (dd) $\mathrm{H}_{2} \mathrm{O}(7.3 \mu \mathrm{l})$ and venous blood DNA $(2 \mu \mathrm{l})$. The PCR conditions were an initial denaturation step at $95^{\circ} \mathrm{C}$ for $10 \mathrm{~min}$, followed by 40 cycles of $95^{\circ} \mathrm{C}$ for $20 \mathrm{sec}, 61^{\circ} \mathrm{C}$ for $1 \mathrm{~min}$ and $72^{\circ} \mathrm{C}$ for $30 \mathrm{sec}$, and a final extension step at $72^{\circ} \mathrm{C}$ for $10 \mathrm{~min}$. Melting curves were obtained following a denaturation period at $95^{\circ} \mathrm{C}$ for $60 \mathrm{sec}$ and holding for $30 \mathrm{sec}$ at $60^{\circ} \mathrm{C}$, and initial and final temperatures of 65 and $90^{\circ} \mathrm{C}$, respectively, with a temperature gradient of $0.05^{\circ} \mathrm{C} / \mathrm{sec}$. PCR and HRM analyses were conducted with the LightCyclerNano System (Roche Diagnostics, Basel, Switzerland), and the melting curve and the accuracy of genotyping data were validated by direct sequencing (Fig. 1A).

p73 G4C14-A4T14 polymorphism. Samples for the p73 G4C14-A4T14 genotype were analyzed using PCR with confronting two-pair primers (CTPP) $(11,25)$. The two-pair primers use were forward (F) 1, 5'-CCACGGATGGGTCTG ATCC-3'; reverse (R) 1, 5'-GGCCTCCAAGGGCAGCTT-3'; F2, 5'-CCTTCCTTCCTGCAGAGCG-3'; and R2, 5'-TTAGCC CAGCGAAGGTGG-3' (11). The PCR volume was $15 \mu \mathrm{l}$, and contained 7.5 $\mu 12 \mathrm{X}$ Taq PCR Mastermix (Tiangen Biotech Beijing Co., Ltd., Beijing, China), $2.5 \mu \mathrm{ldd} \mathrm{H}_{2} \mathrm{O}, 1 \mu \mathrm{l}$ each of the above four primers and $1 \mu \mathrm{l}$ venous blood genomic DNA template. The PCR assay was performed in a GeneAmp PCR System 9700 (Applied Biosystems; Thermo Fisher Scientific, Inc., Waltham, MA, USA), and the PCR conditions included an initial denaturation step for $5 \mathrm{~min}$ at $95^{\circ} \mathrm{C}$, followed by 35 cycles of $40 \mathrm{sec}$ at $95^{\circ} \mathrm{C}, 40 \mathrm{sec}$ at $60^{\circ} \mathrm{C}$ and $40 \mathrm{sec}$ at $72^{\circ} \mathrm{C}$, and a final elongation for $10 \mathrm{~min}$ at $72^{\circ} \mathrm{C}(11)$. An aliquot $(8 \mu \mathrm{l})$ of the PCR product was analyzed on $2 \%$ agarose gel with ethidium bromide (50 bp DNA Ladder Marker; Sinopharm Chemical Reagent Co., Ltd., Shanghai, China). The GC homozygote is expected to produce two bands of 428 and $193 \mathrm{bp}$, respectively, while the AT homozygote is expected to produce two bands of 428 and $270 \mathrm{bp}$, respectively, and GC/AT heterozygosity is expected to produce three bands of 428, 270 and $193 \mathrm{bp}$, respectively $(11,24)$. The results of PCR-CTPP genotyping and sequencing analysis were consistent (Fig. 1B).

Statistical analysis. Statistical analyses were performed using the statistical software SPSS 13.0 (SPSS, Inc., Chicago, IL, USA). The frequency of polymorphisms in the p73 and MDM2 genes among cases and clinical outcome was statistically analyzed using the $\chi^{2}$ test. The association between the polymorphisms of these two genes and lung cancer was determined using an unconditional logistic regression model to assess odds ratios (ORs) and 95\% confidence intervals (CIs). $\mathrm{P}<0.05$ was considered to indicate a statistically significant difference.

\section{Results}

Characteristics of the study subjects. In the present case-control study, the frequency distribution of selected characteristics of the subjects is presented in Table I. There were no significant differences in the distributions of age or sex between cases and controls $(\mathrm{P}>0.05)$. However, compared with the control subjects, the cases were more likely to be tobacco smokers $(\mathrm{P}<0.05)$, which indicated that tobacco smoking was a high-risk factor for NSCLC in the present study population.

Distribution of 73 and MDM2 polymorphisms. The genotype and polymorphic allele frequencies of the three polymorphisms 
A
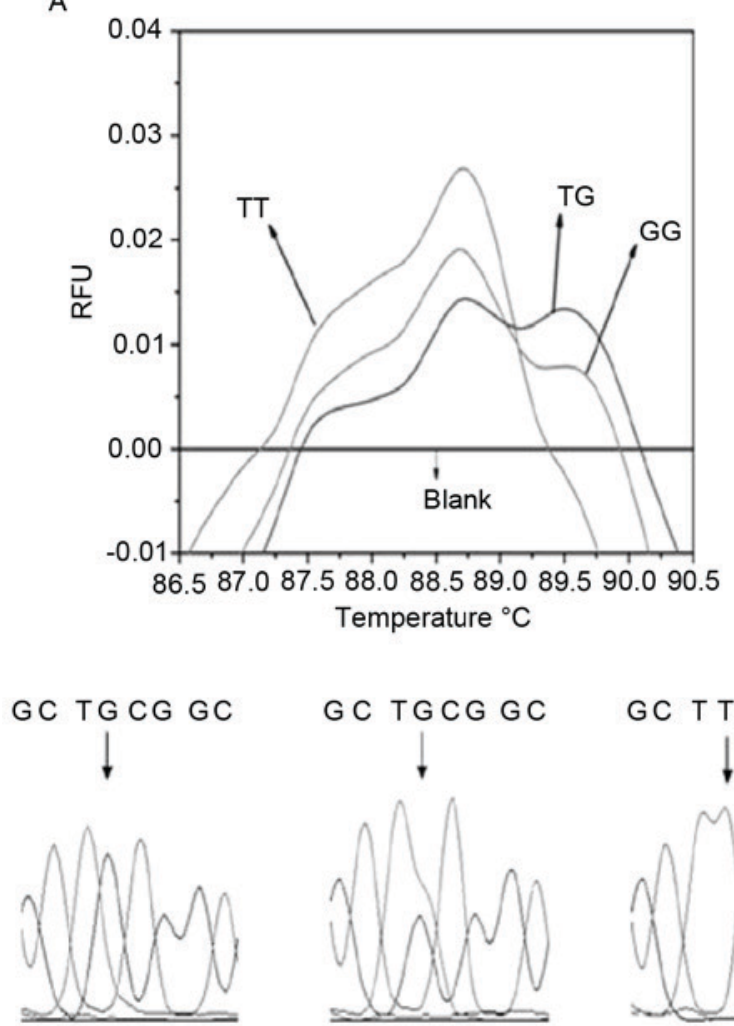

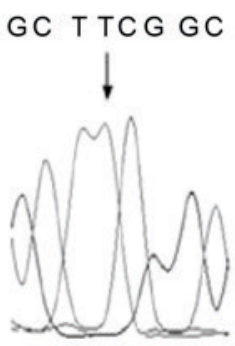

B
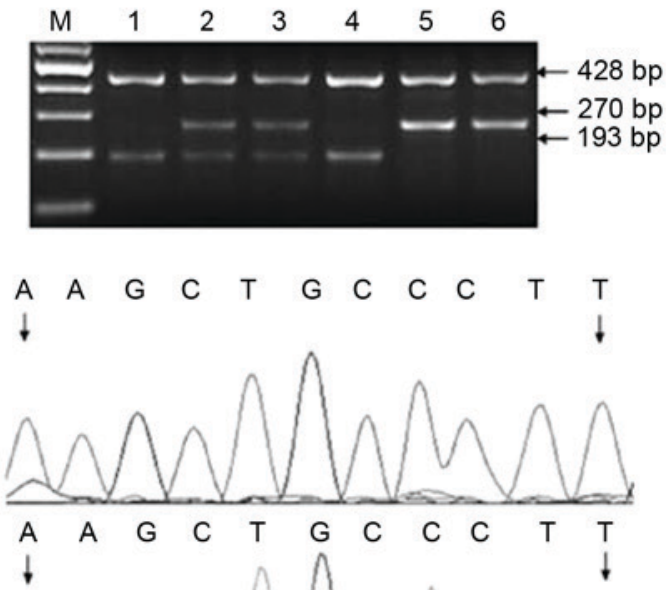

Figure 1. Polymerase chain reaction with confronting two-pair primers, high resolution melting and direct-sequencing results of MDM2 and p73 gene polymorphisms. (A) MDM2 polymorphisms: Three genotypes are indicated by arrows: TT, TG and GG. (B) p73 polymorphisms. Lanes 1 and 4, GC/GC genotype (428 and 193 bp); lanes 2 and 3, GC/AT genotype (428, 270 and 193 bp); and lanes 5 and 6, AT/AT genotype (428 and 270 bp). M, marker; MDM2, murine double minute 2 .

(p73 G4C14-A4T14 and MDM2 309T/G SNPs) between the cases and controls are shown in Table II.

The frequencies of the three genotypes (GC/GC, GC/AT and AT/AT) of p73 G4C14-A4T14 polymorphism in NSCLC cases and controls were 50.54, 43.01 and $6.45 \%$, and 50.00, 36.22 and $13.78 \%$, respectively. There were significant differences in the genotype distributions of p73 G4C14-A4T14 polymorphism between cases and controls $(\mathrm{P}<0.05)$. The frequencies of the three genotypes (GG, TG and TT) of MDM2 309T/G SNPs in NSCLC cases and controls were 31.18, 51.61 and $17.21 \%$, and $22.45,51.53$ and $26.02 \%$, respectively. A similar result was obtained with the MDM2 309T/G SNPs $(\mathrm{P}<0.05)$. Furthermore, the frequencies of the p73 AT and MDM2 G alleles were 27.96 and $56.99 \%$, respectively, among cases, and 31.89 and $48.21 \%$, respectively, among controls. The frequencies the G allele of MDM2 309T/G SNPs were significantly different between cases and controls $(\mathrm{P}<0.05)$. By contrast, there was no difference in the frequencies the AT allele of p73 G4C14-A4T14 (P>0.05).

Association between $p 73$ and MDM2 polymorphisms and NSCLC risk. An unconditional logistic regression model was used to estimate the association between genotypes and the risk of developing NSCLC (Table II). The p73 AT/AT genotype was associated with a decreased risk of developing NSCLC $(\mathrm{OR}=0.46 ; 95 \% \mathrm{CI}=0.22-0.97)$, compared with that of the GC/GC genotype. Similarly, the MDM2 TT genotype was also associated with a decreased risk of developing NSCLC
Table I. Demographic characteristics of non-small cell lung cancer cases and controls.

\begin{tabular}{lccc}
\hline Characteristics & $\begin{array}{c}\text { Cases, } \\
\mathrm{n}(\%)\end{array}$ & $\begin{array}{c}\text { Controls, } \\
\mathrm{n}(\%)\end{array}$ & P-value $^{\mathrm{a}}$ \\
\hline Total & 186 & 196 & \\
Age, years & & & 0.99 \\
$\leq 45$ & $90(48.39)$ & $95(48.47)$ & \\
$>45$ & $96(51.61)$ & $101(51.53)$ & \\
Sex & & & 0.49 \\
Male & $136(73.12)$ & $137(69.90)$ & \\
Female & $50(26.88)$ & $59(30.10)$ & \\
Cigarette smoking & & & $<0.01$ \\
No & $54(29.03)$ & $115(58.67)$ & \\
Yes & $132(70.97)$ & $81(41.33)$ & \\
Alcohol consumption & & & 0.95 \\
No & $122(65.59)$ & $128(65.31)$ & \\
Yes & $64(34.41)$ & $68(34.69)$ & \\
Histology & & & \\
Adenocarcinoma & $108(58.06)$ & 0 & \\
Squamous cell & $60(32.26)$ & 0 & \\
Carcinoma & & 0 & \\
Others & $18(9.68)$ & & \\
\hline
\end{tabular}

${ }^{\text {aTwo-sided }} \chi^{2}$ test. 
Table II. Genotype and allele frequencies of p73 and MDM2 among cases and controls, and their association with the risk of developing non-small cell lung cancer.

\begin{tabular}{|c|c|c|c|c|}
\hline Genotype & $\begin{array}{c}\text { Cases, } n(\%) \\
\quad(n=186)\end{array}$ & $\begin{array}{l}\text { Controls, } \mathrm{n}(\%) \\
\qquad(\mathrm{n}=196)\end{array}$ & P-value & OR $(95 \% \mathrm{CI})^{\mathrm{a}}$ \\
\hline \multicolumn{5}{|l|}{ p73 G4C14-A4T14 } \\
\hline $\mathrm{GC} / \mathrm{GC}$ & $94(50.54)$ & $98(50.00)$ & - & 1.00 (Reference) \\
\hline GC/AT & $80(43.01)$ & $71(36.22)$ & 0.46 & $1.18(0.77-1.80)$ \\
\hline AT/AT & $12(6.45)$ & $27(13.78)$ & 0.04 & $0.46(0.22-0.97)^{\mathrm{b}}$ \\
\hline AT allele frequency & $104(27.96)$ & $125(31.89)$ & - & 1.00 (Reference) \\
\hline GC allele frequency & $268(72.04)$ & $267(68.11)$ & 0.24 & $1.21(0.88-1.65)$ \\
\hline \multicolumn{5}{|l|}{ MDM2 309 T/G } \\
\hline $\mathrm{GG}$ & $58(31.18)$ & $44(22.45)$ & - & 1.00 (Reference) \\
\hline $\mathrm{TG}$ & $96(51.61)$ & $101(51.53)$ & 0.18 & $0.72(0.45-1.17)$ \\
\hline $\mathrm{TT}$ & $32(17.21)$ & $51(26.02)$ & 0.01 & $0.48(0.26-0.86)^{\mathrm{b}}$ \\
\hline $\mathrm{G}$ allele frequency & $212(56.99)$ & $189(48.21)$ & - & 1.00 (Reference) \\
\hline $\mathrm{T}$ allele frequency & $160(23.01)$ & $203(51.79)$ & 0.02 & $0.70(53-0.94)^{\mathrm{b}}$ \\
\hline
\end{tabular}

${ }^{\mathrm{a}} \mathrm{ORs}$ were adjusted for age, sex, cigarette smoking and alcohol consumption. ${ }^{\mathrm{b}} \mathrm{P}<0.05$. OR, odds ratio; $\mathrm{CI}$, confidence interval; MDM2, murine double minute 2 .

Table III. Risk of lung cancer in association with MDM2 SNP309 and p73 G4C14-to-A4T14 polymorphism.

\begin{tabular}{|c|c|c|c|c|c|}
\hline p73 genotype & MDM2 genotype & $\begin{array}{c}\text { Cases, } n(\%) \\
\quad(n=186)\end{array}$ & $\begin{array}{c}\text { Control, n }(\%) \\
\quad(n=196)\end{array}$ & P-value & OR $(95 \% \mathrm{CI})^{\mathrm{a}}$ \\
\hline $\mathrm{GC} / \mathrm{AT}+\mathrm{GC} / \mathrm{GC}$ & $\mathrm{GG}+\mathrm{TG}$ & $144(77.42)$ & $132(67.35)$ & - & 1.00 (Reference) \\
\hline $\mathrm{GC} / \mathrm{AT}+\mathrm{GC} / \mathrm{GC}$ & $\mathrm{TT}$ & $30(16.13)$ & 37 (18.88) & 0.28 & $0.74(0.44-1.27)$ \\
\hline $\mathrm{AT} / \mathrm{AT}$ & $\mathrm{GG}+\mathrm{TG}$ & $10(5.38)$ & $13(6.63)$ & 0.42 & $0.71(0.30-1.66)$ \\
\hline AT/AT & $\mathrm{TT}$ & $2(1.07)$ & $14(7.14)$ & $<0.01$ & $0.13(0.03-0.59)^{\mathrm{b}}$ \\
\hline
\end{tabular}

${ }^{\mathrm{a}} \mathrm{ORs}$ were adjusted for age, sex, cigarette smoking and alcohol consumption. ${ }^{\mathrm{b}} \mathrm{P}<0.05$. OR, odds ratio; $\mathrm{CI}$, confidence interval; MDM2, murine double minute 2 .

$(\mathrm{OR}=0.48 ; 95 \% \mathrm{CI}=0.26-0.86)$, compared with that of the GG genotype. However, the heterozygous genotypes for both polymorphisms (p73 GC/AT or MDM2 TG) were not associated with such risk. p73 GC/AT and GC/GC, or MDM2 TG and GG, were combined the into one group for subsequent analysis. The present study examined whether there was a statistical combination effect between the p73 and MDM2 polymorphisms (Table III). It was observed that controls carrying the p73 AT/AT genotype were more likely to carry the MDM2 TT genotype than the cases (7.14 vs. $1.07 \%$, respectively; $\mathrm{P}<0.05)$. Furthermore, the OR significantly decreased to 0.13 (95\% CI=0.03-0.59) among subjects carrying both the p73 AT/AT and MDM2 TT genotypes.

\section{Discussion}

The present study is a case-control study aimed to detect the association between the p73 G4C14-A4T14 and MDM2 SNP309 polymorphisms, alone or under interaction, and the risk of developing NSCLC in a Southern Chinese population. In the present hospital-based analysis, it was demonstrated that both p73 and MDM2 polymorphisms were associated with a decreased risk of developing NSCLC. Furthermore, the interact was detected between the p73 AT/AT and MDM2 TT genotypes using a multiplicative manner.

p73 has structural and functional homology with the p53 gene, and induces cell cycle arrest or apoptosis in response to DNA damage $(26,27)$. A dinucleotide polymorphism at positions 4 and 14 (G4C14-A4T14) is located at exon 2 of the p73 gene, which possibly forms a stem-loop structure to influence p73 translation and gene expression (5). Although the association between the p73 G4C14-A4T14 polymorphism and the risk of developing cancer has been investigated in a variety of tumors, the results were not consistent $(8-17,28,29)$. Niwa et al (12) and Zhang et al (17) reported that the AT/AT genotype was associated with a significantly increased risk of developing endometrial cancer and lung in Japanese (12) and Northern Chinese (17) populations, respectively. However, Hamajima et al (28) did not identify any associations between this polymorphism and the risk of developing digestive tract cancers, including colorectal cancer, in a Japanese population. Similar results were obtained with lung cancer in Korea (29). 
On the contrary, $\mathrm{Hu}$ et al (16) reported that the AT allele of p73 was associated with a significantly decreased risk of developing lung cancer in a Chinese population. In accordance with this result, the present study also observed a significant association between the p73 G4C14-A4T14 polymorphism and the risk of developing NSCLC, and the frequency of the p73 GC allele among the healthy Chinese was 0.707 , which was similar to that of the healthy Japanese (12). Besides, there was a significant interaction between p73 G4C14-A4T14 and MDM2 309T/G SNPs in NSCLC in a Southern Chinese population.

The 309T/G SNP is a common SNP in the promoter region of the MDM2 gene, which has been demonstrated to increase MDM2 expression by increasing the binding affinity of Sp1 to the promoter of MDM2 $(22,30)$, and represses the transcriptional activity of p73, thus attenuating its activity in G1 cell-cycle control and apoptosis (18-20). It has been reported that individuals carrying the G allele of MDM2 SNP309 were more sensitized to develop both hereditary and sporadic cancers (22). Various studies have reported an increased risk of developing lung cancer for the carriers of the $G$ allele in Korean and Chinese populations $(31,32)$. Previous studies confirmed that the G allele of MDM2 SNP309 was associated with higher expression levels of MDM2 protein (21). In addition, various studies failed to show a significant association between the G allele of MDM2 SNP309 and the risk of developing breast $(33,34)$ or lung cancer $(35)$. In the present case-control study, it was investigated whether the MDM2 309T/G SNPs were associated with the risk of developing NSCLC in a Southern Chinese population. The results revealed that the frequencies of the three genotypes and the allele distributions were significantly different between the NSCLC patients and the healthy controls. In addition, there was a significant difference between the GG and TT genotypes, and subjects carrying the T allele had a significantly decreased risk of developing NSCLC in the current Southern Chinese population compared with that of patients carrying the GG genotype, which was consistent with the results of Jun et al (31). Therefore, these findings further supported the present result that the MDM2 SNP309 $\mathrm{T}$ allele may reduce the risk of developing NSCLC. It could be hypothesized that different molecular pathogeneses in different tumors may cause this discrepancy, which would require further study.

The present study examined whether the p73 gene G4C14-A4T14 polymorphism and the MDM2 gene SNP309 were associated with the risk of developing NSCLC in a Chinese population. Compared with the p73 GC/AT + GC/GC and MDM2 GG + TG genotypes, there was a significant difference in the p73 AT/AT and MDM2 TT genotypes with NSCLC in a Chinese population, and the OR was significantly decreased to 0.13 (95\% CI=0.03-0.59). Therefore, the present results revealed that there was a significant interaction between p73 G4C14-to-A4T14 and MDM2 309T/G SNPs in NSCLC patients within the present Southern Chinese population. However, the small sample size used in the present study caused broad CIs in the regression model. Thus, further larger population-based studies are required to confirm the association of these two polymorphisms with the risk of developing NSCLC in other populations.
In conclusion, the present study demonstrated a significant association in the decreased risk of developing NSCLC between p73 AT/AT and MDM2 TT genotypes. Furthermore, the p73 G4C14-A4T14 and MDM2 309 T/G SNPs possibly had a interaction on the lower risk of developing NSCLC, and these findings may be a protective factor for NSCLC development in Chinese populations.

\section{Acknowledgements}

The present study was supported by funds from the National Natural Science Foundation of China (grant nos. 61171061 and 31501538), the key program of Hunan Provincial Department of Science and Technology (grant no. 2016NK2096), the Natural Science Foundation of Hunan Province (grant no. 2015JJ2049), Changsha Key Science \& Technology Program of Hunan Province of China (grant no. kh1601106), the Scientific Research Fund of Hunan Provincial Education Department (grant nos. 15C0412 and 15C0411) and the Postdoctoral Science Foundation of China (grant nos. 2016T90769, 2015M580707 and 2016M592456). The authors sincerely thank the patients and healthy volunteers for their participation in the present study, as well as the Hunan Provincial Tumor Hospital.

\section{References}

1. Jemal A, Bray F, Center MM, Ferlay J, Ward E and Forman D: Global cancer statistics. CA Cancer J Clin 61: 69-90, 2011.

2. Zhou BB and Elledge SJ: The DNA damage response: Putting checkouts in perspective. Nature 408: 433-439, 2000.

3. Hu ZB, Ma HX, Tan W et al: The research between genetic susceptibility to lung cancer and $\mathrm{p} 73$ gene polymorphism. Chin J Epidemiol 26: 106-109, 2005.

4. Cheng Z, Wang W, Song YN, Kang Y and Xia J: hoGG1, p53 genes and smoking interactions are associated with the development of lung cancer. Asian Pac J Cancer Prev 13: 1803-1808, 2012.

5. Kaghad M, Bonnet H, Yang A, Creancier L, Biscan JC, Valent A, Minty A, Chalon P, Lelias JM, Dumont X, et al: Monoallelically expressed gene related to $\mathrm{p} 53$ at $\mathrm{lp} 36$, a region frequently deleted in neuroblastoma and other human cancers. Cell 90: 809-819, 1997.

6. Melino G, De Laurenzi V and Vousden KH: p73: Friend or foe in tumorigenesis. Nat Rev Cancer 2: 605-615, 2002.

7. Peters MA, Janer M, Kolb S, Jarvik GP, Ostrander EA and Stanford JL: Germline mutations in the p73 gene do not predispose to familial prostate-brain cancer. Prostate 48: 292-296, 2001

8. Ryan BM, Mcmanus R, Daly JS, Carton E, Keeling PW, Reynolds JV and Kelleher D: A common p73 polymorphism is associated with a reduced incidence of oesophageal carcinoma. Br J Cancer 85: 1499-1503, 2001

9. Huang XE, Hamajima N, Katsuda N, Matsuo K, Hirose K, Mizutani M, Iwata H, Miura S, Xiang J, Tokudome S and Tajima K: Association of p53 codon Arg72pro and p73 G4C14-to-A4T14 at exon 2 genetic polymorphisms with the risk of Japanese breast cancer. Breast Cancer 10: 307-311, 2003.

10. Li G, Sturgis EM, Wang LE, Chamberlain RM, Amos CI, Spitz MR, El-Naggar AK, Hong WK and Wei Q: Association of a p73 exon 2 G4C14-to-A4T14 polymorphism with risk of squamous cell carcinoma of the head and neck. Carcinogenesis 25: 1911-1916, 2004.

11. Lee KE, Hong YS, Kim BG, Kim NY, Lee KM, Kwak JY and Roh MS: p73 G4C14 to A4T14 polymorphism is associated with colorectal cancer risk and survival. World J Gastroenterol 16: 4448-4454, 2010.

12. Niwa Y, Hamajima N, Atsuta Y, Yamamoto K, Tamakoshi A, Saito T, Hirose K, Nakanishi T, Nawa A, Kuzuya K and Tajima K: Genetic polymorphisms of p73 G4C14-to-A4T14 at exon 2 and p53 Arg72Pro and the risk of cervical cancer in Japanese. Cancer Lett 205: 55-60, 2004.

13. Pfeifer D, Arbman G and Sun XF: Polymorphism of the p73 gene in relation to colorectal cancer risk and survival. Carcinogenesis 26: 103-107, 2005. 
14. Niwa Y, Hirose K, Matsuo K, Tajima K, Ikoma Y, Nakanishi T, Nawa A, Kuzuya K, Tamakoshi A and Hamajima N: Association of p73 G4C14-to-A4T14 polymorphism at exon 2 and p53 Arg72Pro polymorphism with the risk of endometrial cancer in Japanese subjects. Cancer Lett 219: 183-190, 2005.

15. Li G, Wang LE, Chamberlain RM, Amos CI, Spitz MR and Wei Q: p73 G4C14-to-A4T14 polymorphism and risk of lung cancer. Cancer Res 64: 6863-6866, 2004.

16. Hu Z, Miao X, Ma H, Tan W, Wang X, Lu D, Wei Q, Lin D and Shen H: Dinucleotide polymorphism of p73 gene is associated with a reduced risk of lung cancer in a Chinese population. Int $\mathbf{J}$ Cancer 114: 455-460, 2005.

17. Zhang X,Li X, Wu Z,Lin F and Zhou H: The p73 G4C14-to-A4T14 polymorphism is associated with risk of lung cancer in the Han Nationality of North China. Mol Carcinog 52: 387-391, 2013.

18. Ozaki $T$ and Nakagawara A: p73, a sophisticated p53 family member in the cancer world. Cancer Sci 96: 729-737, 2005.

19. Levrero M, De Laurenzi V, Costanzo A, Gong J, Melino G and Wang JY: Structure, function and regulation of p63 and p73. Cell Death Differ 6: 1146-1153, 1999.

20. Zeng X, Chen L, Jost CA, Maya R, Keller D, Wang X, Kaelin WG Jr, Oren M, Chen J and Lu H: MDM2 suppresses p73 function without promoting p73 degradation. Mol Cell Biol 19: 3257-3266, 1999.

21. Lundgren K, Montes de Oca Luna R, McNeill YB, Emerick EP, Spencer B, Barfield CR, Lozano G, Rosenberg MP and Finlay CA: Targeted expression of MDM2 uncouples S phase from mitosis and inhibits mammary gland development independent of p53. Genes Dev 11: 714-725, 1997.

22. Bond GL, Hu W, Bond EE, Robins H, Lutzker SG, Arva NC, Bargonetti J, Bartel F, Taubert H, Wuerl P, et al: A single nucleotide polymorphism in the MDM2 promoter attenuates the $\mathrm{p} 53$ tumor suppressor pathway and accelerates tumor formation in humans. Cell 119: 591-602, 2004.

23. Bougeard G, Baert-Desurmont S, Tournier I, Vasseur S, Martin C, Brugieres L, Chompret A, Bressac-de Paillerets B, Stoppa-Lyonnet D, Bonaiti-Pellie C and Frebourg T: Impact of the MDM2 SNP309 and p53 Arg72Pro polymorphism on age tumor onset in Li-Fraumeni syndrome. J Med Genet 43: 531-533, 2006.

24. Cheng H, Xie L, Hu WJ, et al: Detection of the MDM2 SNP309 by QRT-PCR. J Clin Oncol 16: 577-581, 2011.
25. Wang SS, Guo HY, Dong LL, Zhu XQ, Ma L, Li W and Tang JX: Association between a p73 gene polymorphism and genetic susceptibility to non-small cell lung cancer in the South of China. Asian Pac J Cancer Prev 15: 10387-19391, 2014.

26. Zhu J, Jiang J, Zhou $\mathrm{W}$ and Chen X: The potential tumor suppressor p73 differently regulates cellular p53 target genes. Cancer Res 58: 5061-5065, 1998.

27. Jost CA, Marin MC and Kaelin WG Jr: p73 is a simian [correction of human] p53-related protein that can induce apoptosis. Nature 389: 191-194, 1997.

28. Hamajima N, Matsuo K, Suzuki T, Nakamura T, Matsuura A, Hatooka S, Shinoda M, Kodera Y, Yamamura Y, Hirai T, et al: No association of p73 G4C14-to-A4T14 at exon 2 and p53 Arg72Pro polymorphism with the risk of digestive tract cancers in Japanese. Cancer Lett 181: 81-85, 2002.

29. Choi JE, Kang HG, Chae MH, Kim EJ, Lee WK, Cha SI, Kim CH, Jung TH and Park JY: No association between p73 G4C14-to-A4T14 polymorphism and the risk of lung cancer in a Korean population. Biochem Genet 44: 543-550, 2006.

30. Bond GL, Hirshfield KM, Kirchhoff T, Alexe G, Bond EE, Robins H, Bartel F, Taubert H, Wuerl P, Hait W, et al: MDM2 SNP309 accelerates tumor formation in a gender-specific and hormone-dependent manner. Cancer Res 66: 5104-5110, 2006.

31. Jun HJ, Park SH, Lee WK, Choi JE, Jang JS, Kim EJ, Cha SI, Kim DS, Kam S, Kim CH, et al: Combined effects off p73 and MDM2 polymorphisms on the risk of lung cancer. Mol Carcinog 46: 100-105, 2007.

32. Zhang X, Miao X, Guo Y, Tan W, Zhou Y, Sun T, Wang Y and Lin D: Genetic polymorphisms in cell cycle regulatory genes MDM2 and TP53 are associated with susceptibility to lung cancer. Hum Mutat 27: 110-117, 2006.

33. Ma H, Hu Z, Zhai X, Wang S, Wang X, Qin J, Jin G, Liu J, Wang X, Wei Q and Shen H: Polymorphisms in the MDM2 promoter and risk of breast cancer: A case-control analysis in a Chinese population. Cancer Lett 240: 261-267, 2006.

34. Campbell IG, Eccles DM and Choong DY: No association of the MDM2 SNP309 polymorphism with risk of breast or ovarian cancer. Cancer Lett 240: 195-197, 2006.

35. Hu Z, Ma H, Lu D, Qian J, Zhou J, Chen Y, Xu L, Wang X, Wei Q and Shen H: Genetic variants in the MDM2 promoter and lung cancer risk in a Chinese population. Int J Cancer 118: 1275-1278, 2006. 